\title{
Communication \\ Unexplained Syncope: The Importance of the Electrophysiology Study
}

\author{
Ioannis Doundoulakis ${ }^{1,2}{ }^{-}$, Stergios Soulaidopoulos ${ }^{1}$, Petros Arsenos ${ }^{1}$, Polychronis Dilaveris ${ }^{1}{ }^{1}$, \\ Dimitris Tsiachris ${ }^{3}$, Christos-Konstantinos Antoniou ${ }^{1}{ }^{\mathbb{D}}$, Skevos Sideris ${ }^{4}$, Athanasios Kordalis ${ }^{1}$, Ageliki Laina ${ }^{1}$, \\ Sotirios Kallinikidis ${ }^{2}$, Panagiotis Xydis ${ }^{1}$, Stefanos Archontakis ${ }^{1}$, Konstantinos Tsioufis ${ }^{1}$ \\ and Konstantinos A. Gatzoulis $1,5, *$
}

check for

updates

Citation: Doundoulakis, I.; Soulaidopoulos, S.; Arsenos, P.; Dilaveris, P.; Tsiachris, D.; Antoniou, C.-K.; Sideris, S.; Kordalis, A.; Laina, A.; Kallinikidis, S.; et al. Unexplained Syncope: The Importance of the Electrophysiology Study. Hearts 2021, 2,495-504. https://doi.org/10.3390/ hearts2040038

Academic Editor: Gaetano Santulli

Received: 14 September 2021

Accepted: 20 October 2021

Published: 25 October 2021

Publisher's Note: MDPI stays neutral with regard to jurisdictional claims in published maps and institutional affiliations.

Copyright: (c) 2021 by the authors. Licensee MDPI, Basel, Switzerland. This article is an open access article distributed under the terms and conditions of the Creative Commons Attribution (CC BY) license (https:// creativecommons.org/licenses/by/ $4.0 /)$.
1 First Department of Cardiology, National and Kapodistrian University, "Hippokration” Hospital, 11527 Athens, Greece; doudougiannis@gmail.com (I.D.); soulaidopoulos@hotmail.com (S.S.); arspetr@otenet.gr (P.A.); hrodil1@yahoo.com (P.D.); ckantoniou@hotmail.gr (C.-K.A.); akordalis@gmail.com (A.K.); agelikilaina@hotmail.com (A.L.); panosxydis@yahoo.gr (P.X.); stef6arch@yahoo.com (S.A.); ktsioufis@gmail.com (K.T.)

2 Department of Cardiology, 424 General Military Hospital, 54124 Thessaloniki, Greece; sotoskal@hotmail.com 3 Athens Heart Center, Athens Medical Center, 11526 Athens, Greece; dtsiachris@yahoo.com

4 State Department of Cardiology, "Hippokration" Hospital, 11528 Athens, Greece; skevos1@otenet.gr

5 Konstantinos A. Gatzoulis, 181 Dorieon str., P.O. Box 175, 19009 Athens, Greece

* Correspondence: kgatzoul@med.uoa.gr; Tel.: +30-694-4580369

Abstract: Syncope of cardiac origin may be associated with an increased risk of sudden cardiac death if not treated in a timely and appropriate manner. The diagnostic approach of syncope imposes a significant economic burden on society. The investigation and elucidation of the pathogenetic mechanism of syncope are of great clinical importance, as both prognosis and appropriate therapeutic approaches depend on these factors. The responsible mechanism of presyncope or syncope can only be revealed through the patient history, baseline clinical examination and electrocardiogram. The percentage of patients who are diagnosed with these tests alone exceeds $50 \%$. In patients with a history of organic or acquired heart disease or/and the presence of abnormal findings on the electrocardiogram, a further diagnostic electrophysiology inclusive approach should be followed to exclude life threatening arrhythmiological mechanism. However, if the patient does not suffer from underlying heart disease and does not show abnormal electrocardiographic findings in the electrocardiogram, then the probability in the electrophysiology study to find a responsible cause is small but not absent. The role of a two-step electrophysiology study inclusive risk stratification approach for the effective management of the former is thoroughly discussed in this review.

Keywords: syncope; presyncope; pacemaker; electrophysiology study; sinus node dysfunction; atrioventricular node disease

\section{Introduction}

Syncope is a clinical syndrome defined as the transient loss of consciousness, associated with the inability to maintain postural tone and accompanied by a fall to the ground, with rapid and spontaneous recovery. It is caused by a period of inadequate cerebral nutrient flow, most often the result of various factors causing an abrupt drop of systemic blood pressure. Typically, the inadequate cerebral blood flow is of relatively brief duration (at least $8 \mathrm{~s}$ ) and, in syncope, is, by definition, spontaneously self-limited [1,2].

Presyncope is the prodromal phase of syncope, characterized by dizziness, lightheadedness, weakness, nausea, with transient alteration of consciousness, without complete loss, and without necessarily falling on the ground [2]. Syncope of cardiac origin, whether arrhythmic or mechanic obstructive, may be associated with an increased risk of sudden cardiac death if not treated in a timely and appropriate fashion $[3,4]$. The role of a two-step 
electrophysiology study inclusive risk stratification approach for the effective management of the former is thoroughly discussed in this review.

\section{Significance}

The diagnostic approach of syncope implies a notable economic burden on society $[5,6]$. Healthcare expenditure is essential since syncope is an ordinary symptom with a variety of underlying causes leading to patient visits to physicians, the emergency department, and to hospitalizations after syncope [7]. Syncope was the fifth most common reason for an emergency department visit in the United Kingdom according to the Hospital Episode Statistics 2011-2012. The diagnostic tests undertaken to determine the cause of syncope are important drivers of the cost.

Updated guidelines and/or consensus documents display recommendations on which diagnostic tests are most relevant and likely to lead to a diagnosis while, at the same time, less effective measures can be replaced [2,8]. Guidelines are dynamic documents that are updated as new research produces evidence that justifies changes in recommendations. However, the dissemination and permeation of the meanings of guidelines and expert consensus documents are far from satisfactory, and clinical practice adjusts slowly [9].

The investigation and elucidation of the pathogenetic mechanism of syncope or presyncope are of great clinical importance, as both prognosis and appropriate therapeutic approach depend on these factors. The clarification and identification of cardiac-induced syncope or presyncope are essential because many arrhythmias as well as other cardiac disorders implicated in these episodes can be effectively treated. In addition, an episode of loss of consciousness may often be the first symptom of an underlying cardiac disorder [2]

The episodes of loss of consciousness (either partial or complete) of unknown etiology constitute a common clinical problem that may be encountered by physicians of different specialties or general practitioners. Such episodes are the reason for presentation in $3 \%$ of all patients visiting the outpatient department and the reason for hospitalization in 1-6\% of those, who need to be hospitalized [10-12]. It has been estimated that $30 \%$ of the general population will experience such an episode during their lifetime [13]. Framingham's study reported that 6.2 per 1000 patients/year presented with first-episode syncope [13]. Among them, 30\% will experience similar episodes in future, and, in approximately $10 \%$, an underlying cardiac cause will be diagnosed [14]. Studies undertaken in Europe and Japan share similar results, showing that such cases account for the $1-3.5 \%$ of all cases presenting in the emergency department [15].

\section{Epidemiology}

The incidence of these episodes is higher in younger as well as in advanced aged populations. In a study of 268 patients, electrophysiology evaluation revealed positive findings in $38 \%$ in general and $50 \%$ in the subgroup of patients older than 70 years. Growing age correlated with increased diagnostic value of the electrophysiology examination $[3,16]$.

Recurrent episodes of loss of consciousness occur in approximately $30 \%$ of patients with at least one episode in the past $[2,4,13,14,17,18]$. The majority of these cases are not life-threatening, as they usually do not have serious neurological or cardiological background. However, it is worth noting here that the occurrence of cardiac-induced syncope or presyncope is correlated with worse prognosis and 50\% 5-year survival rate, unless appropriate treatment is applied $[1,10]$. In the majority of patients with sudden cardiac death, the main cause is ventricular tachycardia, often triggered by acute coronary syndromes in patients without until then known heart disease, or associated with structural heart disease [19]. In the emergency department of some centers, a special syncope assessment unit is available, improving the diagnostic approach and reducing the need for admission of these patients $[20,21]$. 


\section{Consequences}

The episodes of partial or complete loss of consciousness may often induce moderate or severe physical trauma in patients themselves, due to a fall to the ground, as well as trauma to other people and involvement in traffic accidents caused by patients experiencing an episode while driving. Furthermore, the quality of life of patients who experience such episodes, especially if they tend to occur frequently, is reduced, on the one hand, because of the fear of recurrence and, on the other hand, because of the anxiety. Hence, they limit their activities, their performance at work is impaired, and they are overwhelmed with anxiety or may even develop severe psychiatric syndromes, such as depression, neurosis and psychosis. Moreover, these people should not be employed or must leave their jobs if they are employed in specific occupations, such as aircraft pilots, car drivers, or workers with high-altitude tasks, such as building cleaners, builders, crane operators etc. [2,22].

\section{Etiology}

The pathological conditions that cause syncope or presyncope episodes are many and heterogeneous. The episodes can occur if there is a significant reduction in blood flow to the reticular formation of medulla oblongata of short duration (8 to $10 \mathrm{~s}$ ). It has been estimated that cerebral oxygen $\left(\mathrm{O}_{2}\right)$ supply should be reduced below $3.5 \mathrm{~mL}$ per $100 \mathrm{gr}$ tissue per minute $[23,24]$. Normal levels are estimated at $50-60 \mathrm{~mL} / 100 \mathrm{~g} / \mathrm{min}$ and are maintained throughout life by self-regulatory mechanisms of brain homeostasis, while their integrity depends on homeostatic mechanisms for the regulation of blood pressure and heart rate.

The causes are divided into cardiac and non-cardiac. The first are distinguished in turn into obstructive and arrhythmic. Non-cardiac causes include broader categories, such as neurally-mediated or reflex syncope, disorders of the autonomic nervous system (including pharmacogenic orthostatic hypotension), vascular or non-vascular diseases of the central nervous system, metabolic diseases and psychiatric disorders. The majority of patients with presyncope or syncope episodes without suffering from heart disease and with a normal electrocardiogram have more common neurological etiology versus psychiatric diseases (Table 1) [1,2,25].

Table 1. Etiological classification of unexplained syncope [2].

\begin{tabular}{|c|c|c|}
\hline Reflex (Neurally Mediated) Syncope & Orthostatic & Cardiovascular \\
\hline $\begin{array}{l}\text { Vasovagal } \\
\text { - } \quad \text { Orthostatic VVS: standing, less } \\
\quad \text { common sitting } \\
\text { - } \quad \text { Emotional: fear, pain, blood phobia }\end{array}$ & $\begin{array}{l}\text { Primary autonomic failure } \\
\text { - } \quad \text { Pure autonomic failure } \\
\text { - } \quad \text { Multiple system atrophy } \\
\text { - } \quad \text { Parkinson's disease } \\
\end{array}$ & $\begin{array}{l}\text { Tachycardia } \\
-\quad \text { Supraventricular } \\
-\quad \text { Ventricular }\end{array}$ \\
\hline $\begin{array}{ll}\text { Situational } \\
\text { - } & \text { Laughing, cough, sneeze } \\
\text { - } & \text { Gastrointestinal stimulation } \\
& \text { (swallow, defecation) } \\
\text { - } & \text { Urination } \\
-\quad & \text { Post-meals } \\
\text { - } & \text { Post-exercise } \\
\end{array}$ & $\begin{array}{l}\text { Secondary autonomic failure } \\
\text { - } \quad \text { Diabetes, amyloidosis, kidney failure } \\
-\quad \text { Spinal cord injuries } \\
\text { - } \quad \text { Auto-immune autonomic neuropathy } \\
\text { Paraneoplastic autonomic } \\
\quad \text { neuropathy }\end{array}$ & $\begin{array}{l}\text { Bradycardia } \\
-\quad \text { Sinus node dysfunction } \\
-\quad \text { Atrioventricular conduction system } \\
\quad \text { disease }\end{array}$ \\
\hline Carotid Sinus Syndrome (CSS) & \begin{tabular}{ll}
\multicolumn{2}{l}{ Drug-induced } \\
$\bullet \quad$ Vasodilators \\
$-\quad$ Diuretics \\
$-\quad$ Phenothiazine \\
- $\quad$ Antidepressants \\
$\quad$ Alcohol
\end{tabular} & 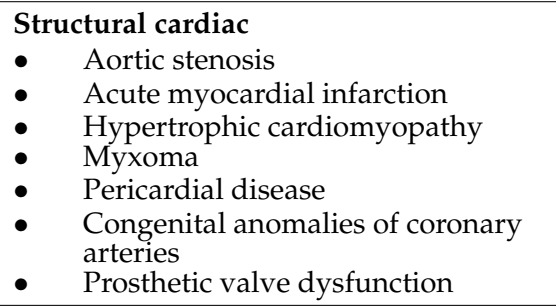 \\
\hline $\begin{array}{l}\text { Non-classical forms } \\
\text { - Without prodromes/without } \\
\text { apparent triggers/atypical } \\
\text { presentation }\end{array}$ & \begin{tabular}{ll}
\multicolumn{2}{l}{ Volume depletion } \\
$\bullet \quad$ Haemorrhage \\
$\bullet \quad$ Diarrhoea \\
$-\quad$ Vomiting
\end{tabular} & $\begin{array}{l}\text { Cardiopulmonary and great vessels } \\
\text { - } \quad \text { Pulmonary embolus, pulmonary } \\
\text { hypertension } \\
\text { - } \quad \text { Acute aortic dissection }\end{array}$ \\
\hline
\end{tabular}




\section{Diagnostic Approach}

The responsible mechanism of presyncope or syncope can only be revealed by history, baseline clinical examination and electrocardiogram $[26,27]$. The echocardiogram or the electroencephalogram offer additional confirmatory help. The percentage of patients who are diagnosed with these tests alone, exceeds $50 \%$.

If the electrocardiogram is within normal limits, the chances of the cause of the presyncope or syncope being an arrhythmia are usually small [28]. If this initial diagnostic approach does not help to reveal the mechanism of episode, further diagnostic tests will have to be performed depending on whether organic heart disease or abnormal electrocardiographic findings coexist. Thus, in patients with a history of organic or acquired heart disease or/and the presence of abnormal findings on the 12-lead or/and 24-h Holter monitoring or/and signal averaged electrocardiogram, a further diagnostic electrophysiology inclusive approach should be followed to exclude life threatening arrhythmiological mechanisms $[29,30]$.

However, if the patient does not suffer from underlying heart disease or does not show abnormal electrocardiographic findings in the 12-lead electrocardiogram or the 24-h Holter monitoring, then the probability in the electrophysiology study to find a responsible cause is small but not absent [31]. Among such elderly syncopal patients, occasionally $\mathrm{HV}$ interval prolongation or/and other atrioventricular node conduction disease criteria or/and carotid sinus syndrome are revealed leading to device therapy [3]. In these cases, the possibility of finding reflex etiology during the tilt table test is more likely, which should be the exam of choice for the examiner [22,32-36].

If the episodes are recurrent and remain unexplained with a negative tilt table test, then special diagnostic techniques of long-term electrocardiographic recording (implantable loop recorder) can be applied, which occasionally reveals the cause and mechanism of these episodes [37-41]. These patients should also be suspected of having a psychiatric condition [42-45], provided a thorough electrophysiology investigation has ruled out the presence of a life threatening and provocative arrhythmia substrate, which can be safely and adequately addressed even among such patients [46].

Although epilepsy is not considered syncope, as it is not associated with transient loss of consciousness, there are reported cases of epilepsy patients responding to antibradycardia pacing [47] while it is well known that some epilepsy patients die suddenly implicating arrhythmia mechanism of central origin [48]. It is uncommon to encounter syncopal patients exhibiting several syncope mechanisms, either benign or potentially malignant during a thorough diagnostic approach [41]. In such cases, the operating mechanism may be revealed by an implantable loop recorder, thus, leading the patient to the safest and most appropriate treatment plan [41].

It has been suggested to follow an implantable loop recorder policy in cases of suspected arrhythmic mechanism when the electrophysiology study is non diagnostic. However, recent evidence investigating the prognostic significance of a number of sinus node disease and atrioventricular node conduction disease defined electrophysiology criteria of positivity, which are thus far non-proposed in the guidelines, suggest the early implantation of rhythm management devices [49,50]. It would be interesting to compare such an electrophysiology-guided versus the implantable loop recorder policy in a randomized control trial in terms of cost effectiveness, ethics and safety in the near future $[30,49,50]$.

Based on the diagnostic approach analyzed above, at the "Hippokration" General Hospital of Athens, we follow a two-step diagnostic approach $[27,41,49,50]$. In the first step, which is the non-invasive one, the goal is to increase the sensitivity of the simple 12-lead surface electrocardiogram in combination with signal-averaged electrocardiogram (SAECG) and the 24-h Holter monitoring. Findings from these two methods that guide the diagnostic tactics to investigate the possibility of serious presyncope or syncope arrhythmic causes are the following. 


\subsection{A. Standard 12-Lead Body Surface Electrocardiography (ECG)}

The 12-lead ECGs were analyzed and divided in the following categories according to the pathological findings:

1. Sinus bradycardia with a heart rate $<60 \mathrm{bpm}$.

2. Presence of left anterior (LAFB) or left posterior fascicular block (LPFB) or complete right bundle brunch block (RBBB).

3. Presence of left bundle branch block (LBBB).

4. Presence of first degree atrioventricular block with PR interval $>200 \mathrm{~ms}$.

5. Presence of bifascicular block (RBBB with either LAFB or LPFB, first degree AV block with either LAFB or LPFB).

6. Presence of trifascicular block (RBBB and first degree atrioventricular block combined with either LAFB or LPFB).

7. Presence of LBBB with first degree atrioventricular block.

8. Presence of right ventricular repolarization abnormalities such as ST segment and $\mathrm{T}$ wave changes in right precordial leads V1-V2-V3, indicative of Brugada syndrome or arrhythmogenic right ventricular cardiomyopathy with epsilon wave (ARVC).

9. Presence of delta waves.

10. Presence of $\mathrm{Q}$ waves or poor $\mathrm{R}$ wave progression in the precordial leads, indicative of an old myocardial infarction.

11. Presence of late potentials (LPs) in the signal-averaged electrocardiogram (SAECG).

12. "Dagger-like" $\mathrm{Q}$ waves in inferior +/ - lateral leads and deep inverted precordial T waves in apical hypertrophic cardiomyopathy.

\subsection{B. 24-h ECG Holter Monitoring}

24-h Holter monitor recordings were analyzed and divided to the following categories according to the results:

1. Mean 24-h heart rate (day and night) $<60 \mathrm{bpm}$, indicative of persistent sinus bradycardia pointing to sinus node disease as the arrhythmia cause of transient loss of consciousness [49].

2. Presence of episodes of supraventricular tachycardia with a heart rate $>140 \mathrm{bpm}$ [41].

3. Presence of frequent complex premature ventricular contractions $(\geq 30 \mathrm{bpm})$, isolated, in form of pairs and or in form of non-sustained ventricular tachycardia (NSVT) ( $\geq 3$ beats with heart rate $\geq 120 \mathrm{bpm}$ ) [51,52].

4. Presence of sinus pauses of $\geq 2$ and $\leq 2.5 \mathrm{~s}$.

5. Episodes of second degree atrioventricular block type I or type II, including 2:1 atrioventricular block [50].

6. Presence of non-conducted premature atrial conductions.

In patients who have a history of either known organic heart disease, or at least one of the above noninvasive ECG findings in the absence of such a known disease, we proceed to the second step of the diagnostic approach, which is the electrophysiology study (Figure 1) [27]. In this step, the application of extended electrophysiology criteria, which, although not included in the current guidelines for the selection of patients for implantation of an anti-bradycardia pacemaker, can contribute to the early detection and selection of these patients. During the study, the following parameters were tested in an attempt to increase the sensitivity of the method again as studies have shown in the past $[3,53,54]$ :

\subsection{Electrophysiology Study}

1. Snus node function.

(a) Corrected sinus node recovery time (CSNRT) $\geq 525 \mathrm{~ms}$.

(b) Sinoatrial conduction time (SACT) $\geq 140 \mathrm{~ms}$.

(c) Chronotropic response to atropine or isoproterenol $\leq 90 \mathrm{bpm}$. 


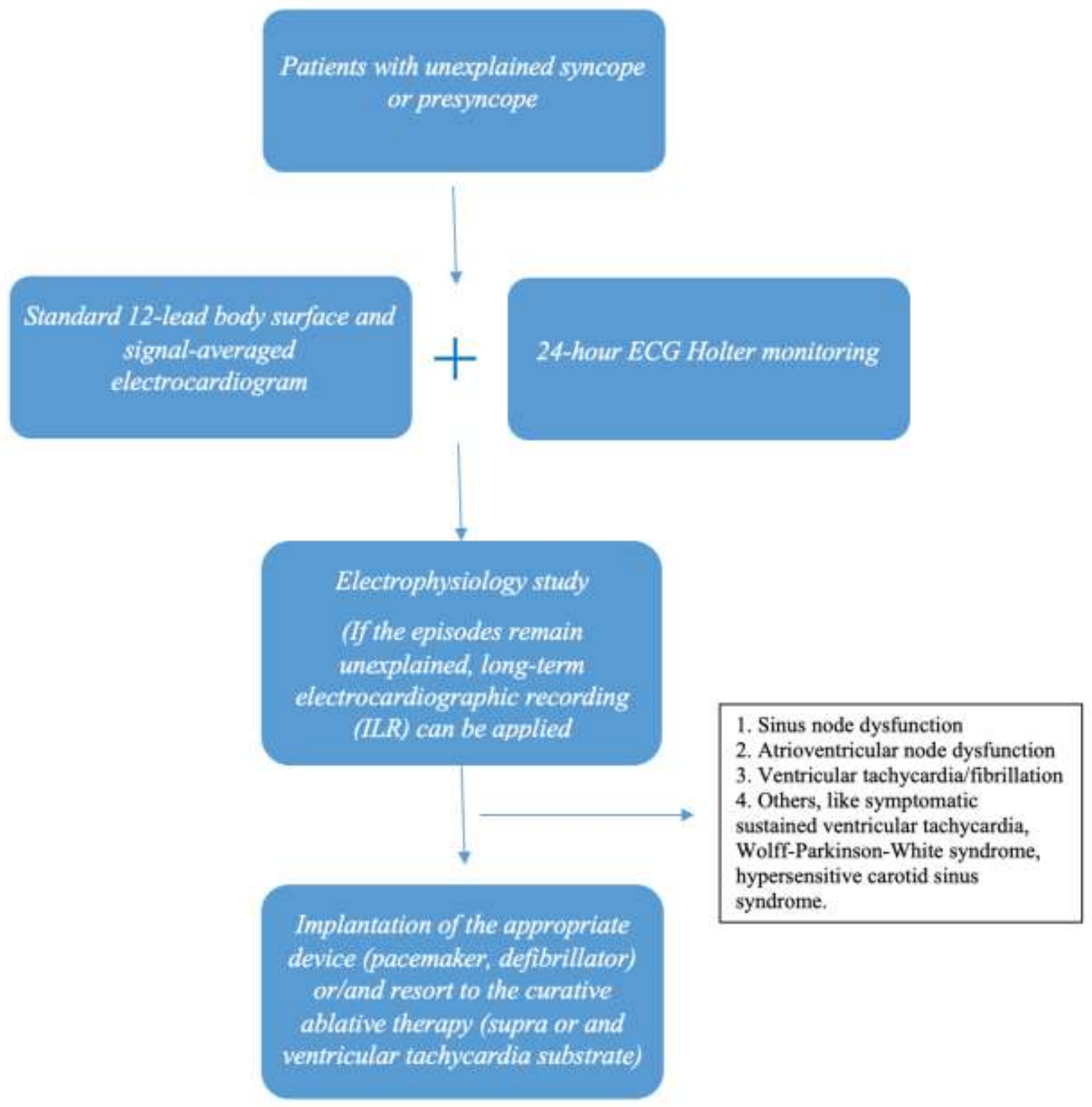

Figure 1. The steps of the diagnostic approach in patients with unexplained syncope.

2. Atrioventricular node and His bundle function.

(a) HV interval $\geq 60$ ms.

(b) Weckenbach phenomenon and 2:1 atrioventricular block $\geq 500$ and $400 \mathrm{~ms}$, respectively.

(c) Atrioventricular node effective refractory period $\geq 450 \mathrm{~ms}$.

(d) Presence of split His potentials.

(e) Induction of infranodal block in atrial pacing.

(f) Induction of bifascicular or trifascicular block in atrial pacing.

3. Programmed ventricular stimulation with extra stimuli: Induction of sustained ventricular tachyarrhythmia requiring either antitachycardia pacing or shock for its termination.

4. Programmed supraventricular stimulation with extra stimuli inducing symptomatic sustained supraventricular tachyarrhythmia.

5. In the presence of apparent preexcitation (delta wave) with an antegrade effective refractory period of the accessory connection fast enough ( $\leq 250 \mathrm{~ms})$, its elimination through radiofrequency catheter ablation at the same electrophysiology session should follow. 
6. Carotid sinus massage: The test is characterized as abnormal if pauses $\geq 3 \mathrm{~s}$ occur [55].

The following conditions were considered as abnormal findings of the electrophysiological study:

1. Sinus node dysfunction.

2. Atrioventricular node dysfunction.

3. Ventricular tachycardia/fibrillation induction.

4. Others, such as symptomatic sustained ventricular tachycardia induction, WolffParkinson-White syndrome (WPW), hypersensitive carotid sinus syndrome.

Sinus node dysfunction was defined as the presence of sinus bradycardia in standard 12-lead ECG or in 24-h Holter monitoring combined with the detection of at least one abnormal parameter associated with sinus node dysfunction in an electrophysiological study [49].

Atrioventricular node dysfunction was defined as the presence of at least one abnormal parameter in the atrioventricular node function assessment during electrophysiological study [50]. The presence of increased likelihood of developing ventricular tachycardia/fibrillation was defined as the reproduction of sustained ventricular tachycardia and/or fibrillation in electrophysiology study.

\section{Future Perspectives}

Implantation of a permanent pacemaker is a therapeutic intervention commonly employed when a bradycardic etiology is revealed in the clinical and laboratory workup of the patient with syncope, and there are different levels of recommendation according to particular pathophysiologic substrates-including atrioventricular block, sinus node dysfunction, vasovagal syncope etc. The official guideline recommendations for permanent pacing are based on observational studies [56-58] and not on randomized clinical studies, and the evidence of electrophysiology study (EPS) to assess atrioventricular node conduction disease or/and sinus node disease in patients with syncope depends only on the baseline $\mathrm{H}-\mathrm{V}$ interval, second- or third-degree His-Purkinje block during incremental atrial pacing or with pharmacological challenge and prolongation of the corrected sinus node recovery time [2,59].

Other means of EPS-derived evidence of atrioventricular node conduction disease or/and sinus node disease, such as the point of effective refractory period of the atrioventricular node, split his activity or the appearance of bifascicular block on atrial stimulation, sinoatrial conduction time (SACT) and the chronotropic response to atropine [27], have not been included in the European and American guidelines for the management of unexplained syncope patient $[2,59,60]$. Furthermore, we still lack clear answers to seemingly simple questions including the appropriate use of EPS and the exact criteria for pacing based on the results.

\section{Conclusions}

Among patients with a history of unexplained syncope, a set of positivity criteria for the presence of electrophysiology study defined atrioventricular node disease or/and sinus node disease identifies a subset of patients who will benefit from permanent pacing. A randomized control study of a combined electrophysiology study inclusive guided approach is needed in order to better define the best strategy of treating such patients, namely with electrophysiology study guidance or an implantable loop recorder documentation policy or even a combination of these in a more systematic diagnostic approach [58].

Author Contributions: All authors contribute equally. All authors have read and agreed to the published version of the manuscript.

Funding: Study has received unrestricted educational grants from Raycap.

Informed Consent Statement: Not applicable. 
Conflicts of Interest: The authors declare no conflict of interest.

\section{References}

1. Kapoor, W.N. Syncope. N. Engl. J. Med. 2000, 343, 1856-1862. [CrossRef]

2. Brignole, M.; Moya, A.; de Lange, F.J.; Deharo, J.C.; Elliott, P.M.; Fanciulli, A.; Fedorowski, A.; Furlan, R.; Kenny, R.A.; Martin, A.; et al. 2018 ESC Guidelines for the diagnosis and management of syncope. Eur. Heart J. 2018, 39, 1883-1948. [CrossRef]

3. Giannopoulos, G.; Kossyvakis, C.; Panagopoulou, V.; Tsiachris, D.; Doudoumis, K.; Mavri, M.; Vrachatis, D.; Letsas, K.; Efremidis, M.; Katsivas, A.; et al. Permanent pacemaker implantation in octogenarians with unexplained syncope and positive electrophysiologic testing. Heart Rhythm 2017, 14, 694-699. [CrossRef] [PubMed]

4. Bass, E.B.; Elson, J.J.; Fogoros, R.N.; Peterson, J.; Arena, V.C.; Kapoor, W.N. Long-term prognosis of patients undergoing electrophysiologic studies for syncope of unknown origin. Am. J. Cardiol. 1988, 62, 1186-1191. [CrossRef]

5. Sutton, R.; Benditt, D.G. Epidemiology and economic impact of cardiac syncope in western countries. Future Cardiol. 2012, 8, 467-472. [CrossRef]

6. Shiyovich, A.; Munchak, I.; Zelingher, J.; Grosbard, A.; Katz, A. Admission for syncope: Evaluation, cost and prognosis according to etiology. Isr. Med Assoc. J. IMAJ 2008, 10, 104-108.

7. Malasana, G.; Brignole, M.; Daccarett, M.; Sherwood, R.; Hamdan, M.H. The prevalence and cost of the faint and fall problem in the state of Utah. Pacing Clin. Electrophysiol. PACE 2011, 34, 278-283. [CrossRef]

8. Moya, A.; Sutton, R.; Ammirati, F.; Blanc, J.J.; Brignole, M.; Dahm, J.B.; Deharo, J.C.; Gajek, J.; Gjesdal, K.; Krahn, A.; et al Guidelines for the diagnosis and management of syncope (version 2009). Eur. Heart J. 2009, 30, 2631-2671. [CrossRef] [PubMed]

9. O’Dwyer, C.; Hade, D.; Fan, C.W.; Cunningham, C.; Kenny, R.A. How well are European Society of Cardiology (ESC) guidelines adhered to in patients with syncope? Ir. Med J. 2010, 103, 11-14.

10. Kapoor, W.N. Evaluation and outcome of patients with syncope. Medicine 1990, 69, 160-175. [CrossRef] [PubMed]

11. Gendelman, H.E.; Linzer, M.; Gabelman, M.; Smoller, S.; Scheuer, J. Syncope in a general hospital patient population. Usefulness of the radionuclide brain scan, electroencephalogram, and 24-hour Holter monitor. N.Y. State J. Med. 1983, 83, 1161-1165.

12. Day, S.C.; Cook, E.F.; Funkenstein, H.; Goldman, L. Evaluation and outcome of emergency room patients with transient loss of consciousness. Am. J. Med. 1982, 73, 15-23. [CrossRef]

13. Savage, D.D.; Corwin, L.; McGee, D.L.; Kannel, W.B.; Wolf, P.A. Epidemiologic features of isolated syncope: The Framingham Study. Stroke 1985, 16, 626-629. [CrossRef]

14. Gatzoulis, K.; Sideris, S.; Theopistou, A.; Sotiropoulos, H.; Stefanadis, C.; Toutouzas, P. Long-term outcome of patients with recurrent syncope of unknown cause in the absence of organic heart disease and relation to results of baseline tilt table testing. Am. J. Cardiol. 2003, 92, 876-879. [CrossRef]

15. Colman, N.; Nahm, K.; Ganzeboom, K.S.; Shen, W.K.; Reitsma, J.; Linzer, M.; Wieling, W.; Kaufmann, H. Epidemiology of reflex syncope. Clin. Auton. Res. Off. J. Clin. Auton. Res. Soc. 2004, 14 (Suppl. 1), 9-17. [CrossRef] [PubMed]

16. Lu, J.; Lu, Z.; Voss, F.; Schoels, W. Results of invasive electrophysiologic evaluation in 268 patients with unexplained syncope. J. Huazhong Univ. Sci. Technol. 2003, 23, 278-279.

17. Kapoor, W.N.; Karpf, M.; Wieand, S.; Peterson, J.R.; Levey, G.S. A prospective evaluation and follow-up of patients with syncope. N. Engl. J. Med. 1983, 309, 197-204. [CrossRef] [PubMed]

18. Kapoor, W.N.; Peterson, J.; Wieand, H.S.; Karpf, M. Diagnostic and prognostic implications of recurrences in patients with syncope. Am. J. Med. 1987, 83, 700-708. [CrossRef]

19. Huikuri, H.V.; Castellanos, A.; Myerburg, R.J. Sudden death due to cardiac arrhythmias. N. Engl. J. Med. 2001, $345,1473-1482$. [CrossRef] [PubMed]

20. Shen, W.K.; Decker, W.W.; Smars, P.A.; Goyal, D.G.; Walker, A.E.; Hodge, D.O.; Trusty, J.M.; Brekke, K.M.; Jahangir, A.; Brady, P.A.; et al. Syncope Evaluation in the Emergency Department Study (SEEDS): A multidisciplinary approach to syncope management. Circulation 2004, 110, 3636-3645. [CrossRef]

21. Kenny, R.A.; Brignole, M.; Dan, G.A.; Deharo, J.C.; van Dijk, J.G.; Doherty, C.; Hamdan, M.; Moya, A.; Parry, S.W.; Sutton, R.; et al. Syncope Unit: Rationale and requirement-the European Heart Rhythm Association position statement endorsed by the Heart Rhythm Society. Ep Eur. 2015, 17, 1325-1340. [CrossRef]

22. Gatzoulis, K.A.; Mamarelis, I.I.; Theopistou, A.M.; Sideris, S.K.; Avgeropoulou, K.; Gialafos, J.H.; Toutouzas, P.K. Tilt-Table Testing in Syncopal Patients with Sick Sinus Syndrome: A Guide to Pathophysiology and Management? Ann. Noninvasive Electrocardiol. 1999, 4, 115-120. [CrossRef]

23. McHenry, L.C., Jr.; Fazekas, J.F.; Sullivan, J.F. Cerebral hemodynamics of syncope. Am. J. Med Sci. 1961, 241, 173-178. [CrossRef]

24. Gibson, G.E.; Pulsinelli, W.; Blass, J.P.; Duffy, T.E. Brain dysfunction in mild to moderate hypoxia. Am. J. Med. 1981, 70, 1247-1254. [CrossRef]

25. Goldstein, D.S.; Spanarkel, M.; Pitterman, A.; Toltzis, R.; Gratz, E.; Epstein, S.; Keiser, H.R. Circulatory control mechanisms in vasodepressor syncope. Am. Heart J. 1982, 104, 1071-1075. [CrossRef]

26. Alboni, P.; Brignole, M.; Menozzi, C.; Raviele, A.; Del Rosso, A.; Dinelli, M.; Solano, A.; Bottoni, N. Diagnostic value of history in patients with syncope with or without heart disease. J. Am. Coll. Cardiol. 2001, 37, 1921-1928. [CrossRef] 
27. Gatzoulis, K.A.; Karystinos, G.; Gialernios, T.; Sotiropoulos, H.; Synetos, A.; Dilaveris, P.; Sideris, S.; Kalikazaros, I.; Olshansky, B.; Stefanadis, C.I. Correlation of noninvasive electrocardiography with invasive electrophysiology in syncope of unknown origin: Implications from a large syncope database. Ann. Noninvasive Electrocardiol. 2009, 14, 119-127. [CrossRef] [PubMed]

28. Krol, R.B.; Morady, F.; Flaker, G.C.; DiCarlo, L.A., Jr.; Baerman, J.M.; Hewett, J.; de Buitleir, M. Electrophysiologic testing in patients with unexplained syncope: Clinical and noninvasive predictors of outcome. J. Am. Coll. Cardiol. 1987, 10, 358-363. [CrossRef]

29. Gatzoulis, K.A.; Carlson, M.D.; Biblo, L.A.; Rizos, I.; Gialafos, J.; Toutouzas, P.; Waldo, A.L. Time domain analysis of the signal averaged electrocardiogram in patients with a conduction defect or a bundle branch block. Eur. Heart J. 1995, 16, 1912-1919. [CrossRef]

30. Gatzoulis, K.A.; Arsenos, P.; Trachanas, K.; Dilaveris, P.; Antoniou, C.; Tsiachris, D.; Sideris, S.; Kolettis, T.M.; Tousoulis, D. Signal-averaged electrocardiography: Past, present, and future. J. Arrhythmia 2018, 34, 222-229. [CrossRef]

31. Gatzoulis, K.A.; Karystinos, G.; Arsenos, P.; Gialernios, T.; Vouliotis, A.H.; Kritikos, A.; Papadopoulos, A.; Tousoulis, D. An electrophysiology guided approach is useful even among unexplained syncope patients without abnormal electrocardiographic findings or/and systolic ventricular dysfunction. In Proceedings of the (EHRA) EUROPACE-CARDIOSTIM, Milan, Italy, 21-24 June 2015.

32. Abi-Samra, F.; Maloney, J.D.; Fouad-Tarazi, F.M.; Castle, L.W. The usefulness of head-up tilt testing and hemodynamic investigations in the workup of syncope of unknown origin. Pacing Clin. Electrophysiol. PACE 1988, 11, 1202-1214. [CrossRef]

33. Fitzpatrick, A.; Sutton, R. Tilting towards a diagnosis in recurrent unexplained syncope. Lancet 1989, 1, 658-660. [CrossRef]

34. Raviele, A.; Gasparini, G.; Di Pede, F.; Delise, P.; Bonso, A.; Piccolo, E. Usefulness of head-up tilt test in evaluating patients with syncope of unknown origin and negative electrophysiologic study. Am. J. Cardiol. 1990, 65, 1322-1327. [CrossRef]

35. Grubb, B.P.; Temesy-Armos, P.; Hahn, H.; Elliott, L. Utility of upright tilt-table testing in the evaluation and management of syncope of unknown origin. Am. J. Med. 1991, 90, 6-10. [CrossRef]

36. Grubb, B.P.; Wolfe, D.; Temesy-Armos, P.; Hahn, H.; Elliott, L. Reproducibility of head upright tilt table test results in patients with syncope. Pacing Clin. Electrophysiol. PACE 1992, 15, 1477-1481. [CrossRef] [PubMed]

37. Krahn, A.D.; Klein, G.J.; Yee, R.; Skanes, A.C. Randomized assessment of syncope trial: Conventional diagnostic testing versus a prolonged monitoring strategy. Circulation 2001, 104, 46-51. [CrossRef]

38. Farwell, D.J.; Freemantle, N.; Sulke, N. The clinical impact of implantable loop recorders in patients with syncope. Eur. Heart J. 2006, 27, 351-356. [CrossRef] [PubMed]

39. Sulke, N.; Sugihara, C.; Hong, P.; Patel, N.; Freemantle, N. The benefit of a remotely monitored implantable loop recorder as a first line investigation in unexplained syncope: The EaSyAS II trial. 2016, 18, 912-918. Europace 2016, 18, 912-918. [CrossRef]

40. Sideris, S.K.; Mousiama, T.A.; Stougiannos, P.N.; Skiadas, I.P.; Laiou, F.P.; Sotiropoulos, I.K.; Gatzoulis, K.A.; Stefanadis, C.; Kallikazaros, I.E. The role of the implantable loop recorder in the investigation of recurrent syncope. Hell. J. Cardiol. 2009, 50, 155-159.

41. Soulaidopoulos, S.; Arsenos, P.; Doundoulakis, I.; Tsiachris, D.; Antoniou, C.K.; Dilaveris, P.; Fragakis, N.; Sotiriadou, M.; Sideris, S.; Kordalis, A.; et al. Syncope associated with supraventricular tachycardia: Diagnostic role of implantable loop recorders. Ann. Noninvasive Electrocardiol. 2021, e12850. [CrossRef]

42. Kapoor, W.N.; Fortunato, M.; Hanusa, B.H.; Schulberg, H.C. Psychiatric illnesses in patients with syncope. Am. J. Med. 1995, 99, 505-512. [CrossRef]

43. Katon, W. Panic disorder and somatization. Review of 55 cases. Am. J. Med. 1984, 77, 101-106. [CrossRef]

44. Linzer, M.; Felder, A.; Hackel, A.; Perry, A.J.; Varia, I.; Lou Melville, M.; Ranga Krishnan, K. Psychiatric Syncope: A New Look at an Old Disease. Psychosomatics 1990, 31, 181-188. [CrossRef]

45. Linzer, M.; Varia, I.; Pontinen, M.; Divine, G.W.; Grubb, B.P.; Estes, N.A.M. Medically unexplained syncope: Relationship to psychiatric illness. Am. J. Med. 1992, 92, S18-S25. [CrossRef]

46. Gatzoulis, K.; Tsiachris, D.; Balta, G.; Antoniou, C.-K.; Arsenos, P.; Dilaveris, P.; Tousoulis, D. Cardiac rhythm management devices and ablation procedures in psychiatric patients: A case series and review of the literature. Heart Mind 2020, 4, 21-25. [CrossRef]

47. Sowden, N.; Booth, C.; Kaye, G. Syncope, Epilepsy and Ictal Asystole: A Case Series and Narrative Review. Heart Lung Circ. 2021, 10.1016/j.hlc.2021.07.003. [CrossRef]

48. Baranchuk, A.; Nault, M.A.; Morillo, C.A. The central nervous system and sudden cardiac death: What should we know? Cardiol. J. 2009, 16, 105-112. [PubMed]

49. Doundoulakis, I.; Gatzoulis, K.A.; Arsenos, P.; Dilaveris, P.; Skiadas, I.; Tsiachris, D.; Antoniou, C.K.; Soulaidopoulos, S.; Karystinos, G.; Pylarinou, V.; et al. Permanent pacemaker implantation in unexplained syncope patients with borderline sinus bradycardia and electrophysiology study-proven sinus node disease. J. Arrhythmia 2021, 37, 189-195. [CrossRef] [PubMed]

50. Doundoulakis, I.; Gatzoulis, K.A.; Arsenos, P.; Dilaveris, P.; Tsiachris, D.; Antoniou, C.K.; Sideris, S.; Kordalis, A.; Soulaidopoulos, S.; Laina, A.; et al. Permanent pacemaker implantation in unexplained syncope patients with electrophysiology study-proven atrioventricular node disease. Hell. J. Cardiol. 2021. Ahead of Print.

51. Gatzoulis, K.A.; Tsiachris, D.; Arsenos, P.; Archontakis, S.; Dilaveris, P.; Vouliotis, A.; Sideris, S.; Skiadas, I.; Kallikazaros, I.; Stefanadis, C. Prognostic value of programmed ventricular stimulation for sudden death in selected high risk patients with structural heart disease and preserved systolic function. Int. J. Cardiol. 2014, 176, 1449-1451. [CrossRef] 
52. Gatzoulis, K.A.; Tsiachris, D.; Dilaveris, P.; Archontakis, S.; Arsenos, P.; Vouliotis, A.; Sideris, S.; Trantalis, G.; Kartsagoulis, E.; Kallikazaros, I.; et al. Implantable cardioverter defibrillator therapy activation for high risk patients with relatively well preserved left ventricular ejection fraction. Does it really work? Int. J. Cardiol. 2013, 167, 1360-1365. [CrossRef] [PubMed]

53. Teichman, S.L.; Felder, S.D.; Matos, J.A.; Kim, S.G.; Waspe, L.E.; Fisher, J.D. The value of electrophysiologic studies in syncope of undetermined origin: Report of 150 cases. Am. Heart J. 1985, 110, 469-479. [CrossRef]

54. Hess, D.S.; Morady, F.; Scheinman, M.M. Electrophysiologic testing in the evaluation of patients with syncope of undetermined origin. Am. J. Cardiol. 1982, 50, 1309-1315. [CrossRef]

55. Gatzoulis, K.A.; Toutouzas, P.K. Neurocardiogenic syncope: Aetiology and management. Drugs 2001, 61, 1415-1423. [CrossRef]

56. Scheinman, M.M.; Peters, R.W.; Suave, M.J.; Desai, J.; Abbott, J.A.; Cogan, J.; Wohl, B.; Williams, K. Value of the H-Q interval in patients with bundle branch block and the role of prophylactic permanent pacing. Am. J. Cardiol. 1982, 50, 1316-1322. [CrossRef]

57. Morady, F.; Higgins, J.; Peters, R.W.; Schwartz, A.B.; Shen, E.N.; Bhandari, A.; Scheinman, M.M.; Sauvé, M.J. Electrophysiologic testing in bundle branch block and unexplained syncope. Am. J. Cardiol. 1984, 54, 587-591. [CrossRef]

58. Moya, A.; García-Civera, R.; Croci, F.; Menozzi, C.; Brugada, J.; Ammirati, F.; Del Rosso, A.; Bellver-Navarro, A.; Garcia-Sacristán, J.; Bortnik, M.; et al. Diagnosis, management, and outcomes of patients with syncope and bundle branch block. Eur. Heart J. 2011, 32, 1535-1541. [CrossRef] [PubMed]

59. Shen, W.K.; Sheldon, R.S.; Benditt, D.G.; Cohen, M.I.; Forman, D.E.; Goldberger, Z.D.; Grubb, B.P.; Hamdan, M.H.; Krahn, A.D.; Link, M.S.; et al. 2017 ACC/AHA/HRS Guideline for the Evaluation and Management of Patients With Syncope: Executive Summary: A Report of the American College of Cardiology/American Heart Association Task Force on Clinical Practice Guidelines and the Heart Rhythm Society. Circulation 2017, 136, e25-e59. [CrossRef] [PubMed]

60. Gulamhusein, S.; Naccarelli, G.V.; Ko, P.T.; Prystowsky, E.N.; Zipes, D.P.; Barnett, H.J.; Heger, J.J.; Klein, G.J. Value and limitations of clinical electrophysiologic study in assessment of patients with unexplained syncope. Am. J. Med. 1982, 73, 700-705. [CrossRef] 